\title{
Movência para o sujeito tradutor e a língua nacional
}

\author{
Beatriz Caldas*
}

\section{Introdução}

Este trabalho é parte de uma reflexão a respeito da tradução no Brasil na segunda metade do século XX. Nossa perspectiva de investigação é fundamentada nas construções teóricas de Michel Pêcheux, formuladas a partir de 1969, dentro do que se denominou Análise do Discurso, transpostas para o cenário acadêmico brasileiro por Eni Orlandi a partir da década de 80.

Para a Análise do Discurso o que está em jogo são os efeitos de sentidos e não a transmissão de informações. A e B correspondem às posições de sujeito no discurso e não aos falantes propriamente ditos. Para a Análise do Discurso, a questão dos efeitos de sentidos vincula-se ao fato de que as palavras e expressões mudam de sentido conforme as posições dos sujeitos nos discursos. Quais seriam, então, para os tradutores, os efeitos de sentidos das palavras e expressões 'fidelidade' / 'liberdade' / 'brasileiro' / 'estrangeiro' / 'língua materna' / 'língua estrangeira' , / 'língua nacional' / 'língua brasileira', ou como postula a Análise do Discurso, dos recortes ${ }^{1}$ relevantes para o tema da pesquisa e que respondem às perguntas do dispositivo analítico? Ou seja, como esses sentidos produzem efeitos no corpus pesquisado?

O objeto de nosso estudo é o discurso sobre a tradução na segunda metade do século XX. Adotamos o conceito discurso sobre a tradução em

\footnotetext{
${ }^{*}$ Universidade do Estado do Rio de Janeiro.

${ }^{1}$ Essas perguntas atuam como chaves para o dispositivo analítico. As respostas às perguntas são os recortes que fazemos em nosso corpus. Um recorte é o resultado da relação entre a pergunta básica do analista e o material da análise. Os recortes "indicam características dos processos de significação" (Orlandi, 2003, p.11) e, podem suscitar outros recortes como objeto de observação dos processos discursivos. O analista do discurso faz uso do dispositivo teórico, o repertório teórico de conceitos básicos da $\mathrm{AD}$, e também do dispositivo analítico assim constituído. Seu trabalho é um contínuo entretecer entre o dispositivo teórico e o dispositivo analítico, criado por cada analista para sua análise.
} 
relação ao discurso da tradução a partir das reflexões de Orlandi (1990) em torno de discurso sobre o Brasil e discurso do Brasil:

\begin{abstract}
Consideramos que os 'discursos sobre' são uma das formas cruciais da institucionalização dos sentidos. É no 'discurso sobre' que se trabalha o conceito da polifonia. Ou seja, o "discurso sobre" é um lugar importante para organizar as diferentes vozes (dos discursos de). Assim, o discurso sobre o samba, o discurso sobre o cinema é parte integrante da arregimentação (interpretação) dos sentidos do discurso do samba, do cinema etc. O mesmo se passa com o discurso sobre o Brasil (no domínio da história). Ele organiza, disciplina a memória e a reduz. (Orlandi, 1990 nota de rodapé, p. 37, grifos nossos)
\end{abstract}

À medida que os discursos sobre organizam a institucionalização dos sentidos, podemos compreender discurso sobre a tradução como constituído por processos ideológicos aí construídos, vindo a integrar os discursos da tradução organizada ao longo do século XX, em um movimento contínuo. Compreendemos que nossa pesquisa procura explicitar a historicidade, a movência, o vir a ser dos discursos de e sobre tradução ao longo desse período.

O trabalho apresentado pesquisa a presença de posições sujeitotradutor brasileiro, e o faz através da investigação em torno dos sentidos de 'fidelidade' em tradução e seus desdobramentos em relação aos sentidos de "língua nacional". Investigamos se as posições sujeito-tradutor brasileiros corresponderiam formações discursivas ${ }^{2}$ próprias, que por sua vez constituiriam um discurso sobre/da tradução, entre outros? Em outras palavras, haveria posições de sujeito-tradutor brasileiro com especificidades sóciohistóricas e linguísticas? E mais, nos discursos produzidos sobre a tradução e $d a$ tradução haveria marcas de uma memória vinculada ao seu momento de institucionalização? Essas são questões que este trabalho objetiva problematizar dentro do período a que se refere e apontar hipóteses como respostas.

\footnotetext{
2 Formações discursivas (FDs) são sítios de significação nos quais o sujeito ancora os sentidos que o constituem e os sentidos do que diz.
} 


\section{O prefácio}

O corpus empírico que constitui a investigação apresentada neste artigo é constituído pelo prefácio de autoria de Aurélio Buarque de Holanda Ferreira para o livro de Paulo Rónai, A Tradução Vivida, lançado em 1975. Paulo Rónai foi o autor do primeiro livro sobre tradução no Brasil, lançado em 1952 (Escola de Tradutores). Escolhemos tal prefácio em função de seu título "O brasileiro Paulo Rónai", cuja combinação de ideias nos pareceu relevante de acordo com o que havíamos estabelecido como guia para nossa investigação, (sentidos de "brasileiro", "estrangeiro" etc.). A assinatura de Aurélio Buarque de Holanda Ferreira como autor do prefácio também pesou em nossa escolha, porquanto seu nome está associado à autoria de um popular dicionário de português lançado no Brasil e também de outro, de inglêsportuguês. Tivemos curiosidade de ler suas próprias palavras a respeito da atividade de tradução.

O prefácio é uma peça comum na edição de livros. Seguem abaixo as definições de "prefácio" de acordo com alguns dicionários:

[Do lat. praefatio (nom.), 'o que se diz no princípio'.] S. $m$. 1. Discurso ou advertência, ordinariamente breve, que antecede uma obra escrita; prefação, preâmbulo, prólogo, proêmio, prolusão, prelúdio, preliminar, introdução, anteâmbulo, antelóquio, exórdio. [Antôn.: posfácio.] 2. Lit. Parte da missa católica que precede imediatamente o cânon. [Cf. prefacio, do v. prefaciar.] (Ferreira, 1975, p. 1129)

substantivo masculino

texto preliminar de apresentação, ger. breve, escrito pelo autor ou por outrem, colocado no começo do livro, com explicações sobre seu conteúdo, objetivos ou sobre a pessoa do autor (Houaiss, 2001, p. 2284)

Ambas as definições apontam para o tamanho do prefácio, sua função, autoria e posição no livro. Uma das definições fornece a etimologia da palavra "praefatio"3 , 'o que se diz no princípio', e que é muito curiosa, pois, na verdade, o prefácio é uma das últimas peças de composição do livro moderno, geralmente escrito após o fim da obra. Este sentido etimológico

\footnotetext{
${ }^{3}$ Verbete do dicionário latino português de Torrinha: praefātīō, ōnis [praefor], f. 1. Acção de falar primeiramente. 2. o que se diz em primeiro lugar, no princípio; prefácio, preâmbulo; considerações prévias. praefatio sacrorum: fórmula pronunciada antes duma cerimônia religiosa. (Torrinha, p. 672).
} 
da palavra "prefácio" está presente como reminiscência do passado do livro. Nas palavras de Compagnon:

\begin{abstract}
Segundo a retórica antiga, o discurso se abria canonicamente, dirigindose de maneira concisa ao leitor ou ao ouvinte, a captatio benevolentiae, afirmando, assim, seu propósito, ou seja, colocar o outro em condições favoráveis, torná-lo indulgente. (Quintiliano acrescentava: atento e dócil). A captatio benevolentiae agia entre dois agentes (dois lugares estruturais em relação ao discurso); ela distribuía os papéis antes que os sujeitos desaparecessem. As epístolas dedicatórias da idade média e do início da imprensa tinham função análoga: definiam uma situação (afetiva, institucional) de escrita e leitura. (Compagnon, 1996, p. 84, grifos nossos)
\end{abstract}

O prefácio se desdobra em outras funções e modos de atrair a atenção do leitor. Pressupõe um livro já escrito e terminado. Assim sendo, o prefácio pode ser uma proposta de método de leitura, uma exposição das intenções do autor, uma retrospectiva do que foi escrito. Pode ser escrito pelo próprio autor do livro, ou por outro autor, e procura estabelecer uma ponte entre o leitor e o título da obra, entre o leitor e a representação de sujeito-autor que o prefaciador deseja oferecer ao leitor, mesmo que por apenas um breve instante, minutos antes das cortinas do palco se abrirem deixando aparecer o livro-espetáculo e, por fim, trazerem à cena, de uma vez por todas, o sujeito autor.

Ainda segundo Compagnon (1996, p. 85), "a certidão de nascimento do prefácio moderno" é a carta escrita por Descartes ao abade Picot, tradutor para o francês de sua obra Princípios da Filosofia, originalmente escrita em latim. Nessa carta, Descartes discorre sobre alguns esclarecimentos, cabendo ao tradutor apresentá-los em um prefácio à obra em francês. A própria carta, porém, foi publicada como prefácio do livro.

Os prefácios, assim como as citações, as epígrafes, as notas de rodapé, o posfácio, entre outros, são os textos que circundam o livro e o delimitam, constituindo o que Compagnon denomina perigrafia, (op. cit., p. 70), a saber: "uma zona intermediária entre o fora do texto e o texto". São depositários do que já foi dito e do que ainda será dito sobre o assunto, uma vez que dizem o já dito de novas formas, valendo-se de novas formulações. $\mathrm{O}$ 
prefácio, lido no início do livro e paradoxalmente escrito após a conclusão da obra, desdobra-se em várias funções. Pode ser uma proposta de método de leitura, uma exposição das intenções do autor, uma retrospectiva do que foi escrito procurando, como já dissemos, estabelecer uma ponte entre o leitor e o título da obra.

Foucault aponta para procedimentos internos ao discurso exercendo seu próprio controle. O primeiro deles é o "comentário": Os prefácios constituem-se dentro do conjunto do livro como "comentários" (Foucault, 1996) ao discurso que perpassa a obra em si.

\begin{abstract}
Em primeiro lugar, o comentário: Suponho, mas sem ter muita certeza, que não há sociedade onde não existam narrativas maiores que se contam, se repetem e se fazem variar; fórmulas, textos, conjuntos ritualizados de discursos que se narram, conforme circunstâncias bem determinadas; coisas ditas uma vez e que se conservam, porque nelas se imagina haver algo como um segredo ou uma riqueza. Em suma, pode-se supor que há, muito regularmente nas sociedades, uma espécie de desnivelamento entre os discursos; os discursos que "se dizem" no correr dos dias e das trocas, e que passam com o ato mesmo que os pronunciou; e os discursos que estão na origem de certo número de atos novos de fala que os retomam, os transformam ou falam deles, ou seja, os discursos que, indefinidamente, para além de sua fórmula são ditos, permanecem ditos e ainda estão por dizer. Nós os conhecemos em nosso sistema de cultura: são os textos religiosos ou jurídicos, são também esses textos curiosos, quando se considera o seu estatuto, e que chamamos de "literários"; em certa medida textos científicos. (Foucault, 1996, p 21, grifos nossos)
\end{abstract}

Do longo recorte de Foucault, depreendemos que os comentários referem-se aos discursos que retomam, transformam e falam, tomando como atemporais os atos de fala que acompanham, consagrando-os com valor de verdade. Segundo este ponto de vista, os prefácios podem ser considerados comentários ao texto principal, dizendo o que já foi dito pelo autor do livro, repetindo, validando, emprestando solidariedade ao autor, projetando seu prestígio e explicando sua obra ao leitor. Em nossa pesquisa, pensamos poder afirmar que o prefácio é uma peça do discurso sobre a tradução, uma vez que circula e valida um conjunto de saberes sobre a tradução. 


\section{Análise}

O corpus empírico em tela é o prefácio de autoria de Aurélio Buarque de Holanda Ferreira para o livro de Paulo Rónai, A Tradução Vivida, lançado em 1975. O título do prefácio é O Brasileiro Paulo Rónai. Os recortes feitos para a análise são constituídos por Sequências Discursivas (SDs) que giram em torno dos sentidos de brasileiro / estrangeiro / língua nacional / língua brasileira / língua estrangeira. Foram recortados no corpus SDs que representem a materialidade de um discurso relacionado à historicidade da tradução na cena brasileira. Servindo-se da análise de sentidos expressos no corpus empírico, a pesquisa busca chegar a discursos sobre a tradução.

Os recortes "indicam características dos processos de significação" (ORLANDI, 2003, p.11), e podem suscitar outros recortes como objeto de observação dos processos discursivos. As perguntas em torno dos sentidos de brasileiro / estrangeiro / língua nacional / língua brasileira / língua estrangeira constituem as chaves de nosso procedimento analítico. Ao percorrer essas etapas, o analista trabalha com seu dispositivo analítico que lhe permite recortar seu objeto empírico e chegar a seu objeto discursivo, às FDs e às formações ideológicas.

Recortamos do corpus empírico as seguintes Sequências Discursivas (SDs), relacionadas à questão brasileiro e sentidos afins (alagoano, húngaro, português, da Europa etc):

SD01 - o brasileiro Paulo Rónai (Rónai, [1975] 1981, p. 11)

SD02 - brasilidade ronaiana (op. cit., p. 11)

SD03 - "intelectual húngaro, escolheu, simultaneamente, a liberdade e o Brasil. Eu, de minha parte, se me fosse dado escolher um compatriota, teria escolhido o Sr. Paulo Rónai" (op. cit., p. 11)

SD04- “O português, como o aprendi / Paulo Rónai conta, fagueiro. / Outra façanha dele eu vi: / aprendeu a ser brasileiro" (op. cit., p. 11)

SD05 -...contato com o povo começava bem cedo, nos bondes... (op. cit., p. 12) 
SD06- ...um passageiro alagoano... (op. cit., p. 12)

SD07 - Pôs-se o meu conterrâneo a conversar com o homem que viera da Europa... (op. cit., p. 12)

SD08- "Está vendo aquele homem com quem eu falei? Pois é alagoano, como eu. Eu sou alagoano, meu amigo. E tenho muitos conhecidos alagoanos. A bem dizer, todo o mundo aqui é de Alagoas." (op. cit., p. 12)

SD09 - ...Paulo Rónai, brasileiro que já o era bem antes de se naturalizar, em 1945. (op. cit., p. 12)

SD10 - ...ensaísta, conferencista (que já tem andado pelo Brasil e pelo estrangeiro)... (op. cit., p. 12)

SD11 - É também do humanista de largas fronteiras; do homem de perfeita formação universitária européia... (op. cit., p. 13)

SD12 - Grande brasileiro, o brasileiro Paulo Rónai. (op. cit., p. 15)

O primeiro dos recortes "brasileiro Paulo Rónai", título do prefácio, constitui o enunciado a partir do qual uma rede parafrástica se organiza ao longo do texto por meios das SDs: "Paulo Rónai, brasileiro que já o era bem antes de se naturalizar, em 1945", "Grande brasileiro, o brasileiro Paulo Rónai". Tangencia, assim, sentidos de adjetivo pátrio que qualificam Paulo Rónai de brasileiro por ter adotado o Brasil como pátria, brasileiro à sua maneira própria, tornado brasileiro pelas circunstâncias da vida que viveu e pelo amor que tinha à língua portuguesa do Brasil. O que torna Paulo Rónai brasileiro não é o fato de ter nascido no Brasil nem o de ser filho de brasileiros, mas sim a maestria com que escreve na língua portuguesa do Brasil. Essa forma de brasilidade é denominada "brasilidade ronaiana", cujo sentido aponta para brasileiro como sendo aquele que entende, fala, lê e escreve com maestria em língua portuguesa do Brasil. 
Por um lado, há praticamente uma unanimidade entre os intelectuais a respeito de Paulo Rónai. É festejado por Guimarães Rosa, Magalhães Júnior, Joel Pontes, Wilson Martins, Carlos Drummond de Andrade, citando somente as referências do prefácio em questão. Por outro, há o Paulo Rónai que viaja no estribo do bonde superlotado, onde se encontra com alagoanos, fala com eles como se fosse um deles sendo até mesmo considerado alagoano por eles. Quais são os sentidos da dicotomia "brasileiro / alagoano"? Os brasileiros sobrepõem-se aos alagoanos, os alagoanos sobrepõem-se aos brasileiros, uma categoria contém a outra? Parecem apontar para duas posições de sujeito distintas dentro do discurso. Os sentidos de "alagoano" alinham-se aos sentidos "nordestino", "pobre", "povão", "inculto". Paulo Rónai também é alagoano, assim considerado por outro alagoano no estribo do bonde em viagem para o Méier. $O$ sentido jocoso "hungaramente" percebido por Rónai, segundo o autor do prefácio, não seria o mesmo se "alagoano" não tivesse sentido diferente de "brasileiro". Mas isso não é tudo: o próprio Aurélio Buarque de Holanda Ferreira é alagoano, de modo que os sentidos de "inculto", "povão", são imediatamente descartados. Qual seria a diferença entre a condição de alagoano de Aurélio Buarque de Holanda Ferreira e do passageiro no estribo do bonde? Ambos são alagoanos, sim, mas o primeiro deles é escritor, lexicógrafo, intelectual, e o segundo, não. Dessa forma, tanto o autor do prefácio quanto Paulo Rónai são intelectuais, mestres, eruditos, com vantagens sobre aquele passageiro alagoano específico que tem o "verbo solto" como único patrimônio intelectual, embora traga consigo o cerne da brasilidade. As duas imagens de homem de "verbo solto" e homem intelectual coexistem dentro da denominação "alagoano", em aparente contradição, o que ressalta a porosidade e instabilidade próprias das fronteiras das FDs, em permanente contato com outras FDs. Abrigam dentro de si as dissidências, as resistências e a dispersão de posições-sujeito conflitantes (INDURSKY. 2000). A figura de Paulo Rónai supera essa dicotomia. É como se fosse alagoano do povo, de "verbo solto", e ao mesmo tempo tão alagoano e intelectual quanto seu admirador Aurélio Buarque de Holanda, com quem divide tarefas de escritor, tradutor e artífice da palavra em língua portuguesa. 


\section{Considerações finais}

O encaminhamento da discussão remete à questão língua e tradução. Paulo Rónai conquista a nacionalidade brasileira pela maestria com que domina a língua portuguesa do Brasil. Para a posição-sujeito Paulo Rónai, a língua é sua pátria. Este sentido de língua parece constituir um dos esteios de discursos sobre a tradução. Em oposição ao discurso religioso vigente do século XVI ao século XVIII no Brasil, no qual a veracidade do texto estava irremediavelmente ligada à questão da fé, autoridade e autoria do texto, com a constituição da nação, a língua passa a representar um dos símbolos de identidade, elemento imaginário de união do país. O sujeito-tradutor procura essa representação linguística ideal e pugna por ela, como se a gramática da língua e seu uso correto fossem naturais e não o resultado históricoideológico de um percurso de ideias linguísticas.

Nessa procura dos traços de identificação do tradutor, na busca por seu rosto, ressalta não só a obra de Paulo Rónai, mas também o que ele representou como sujeito-tradutor. Ocupou posição chave uma vez que é brasileiro por adoção e, ao mesmo tempo, europeu e intelectual. Reúne posições dentro dessa formação discursiva que o privilegiam como representação de um sujeito-tradutor ideal, tanto no Brasil quanto no exterior. No Brasil, um dos sentidos dessa representação é o reconhecimento da existência e relevância da língua portuguesa do Brasil, pois, afinal, ela mereceu que um europeu por ela se apaixonasse e a identificasse com pátria e liberdade. Outro sentido possível é a sua condição de europeu. Dentro do imaginário de um país colonizado como o Brasil, a autoridade intelectual de um europeu é acolhida como grande valor e prestígio e avaliza o que seja a boa tradução brasileira.

Fora do Brasil, a representação do Paulo Rónai é a de um europeu brasileiro, alguém que, por fim, entende o que se passa nesse grande Outro. A representação de Paulo Rónai como sujeito tradutor cai como luva num ambiente pós-guerra em que se busca resgatar valores humanistas, entre os quais a importância da tradução, seja como instrumento de difusão cientifica e cultural, seja para a resolução dos conflitos diplomáticos. 
A visita ao prefácio de um dicionarista brasileiro a respeito de uma das obras de Paulo Rónai aponta para a representação do brasileiro Paulo Rónai como um enunciado que sintetiza um personagem há longo esperado na discursividade brasileira: um estrangeiro que ama e respeita a língua e a literatura do Brasil. Nesse sentido, Paulo Rónai é saudado no prefácio como um homem que transita muito bem entre três posições-sujeito no Brasil: conhece a língua culta da alta literatura brasileira e conversa com os alagoanos nos estribos do bonde que o traz do Méier. Além disso, é oriundo da cultura europeia, a qual o imaginário vigente no Brasil, pais colonizado, empresta historicamente força de autoridade e superioridade. É um tradutor tenaz que acreditou inteiramente nos valores do trabalho e na regulamentação da profissão. Foi uma das maiores figuras da institucionalização dos tradutores no Brasil.

De um passado colonial que abrigava a fidelidade como valor máximo, imbuído da religiosidade e desejo de verdade inerente aos textos sagrados, há uma movimentação ao longo do século XX que culmina com o apreço à maestria da língua nacional, à brasilidade. Novos instrumentos de escrita têm aparecido junto a novas ferramentas de tradução e o tradutor tende a se aproximar cada vez mais das premissas de um sujeito de tecnologia da informática, com todas as consequências que esse movimento possa acarretar. No entanto, ainda assim, apesar das muitas modificações dessa movência, cabe ressaltar que o discurso sobre a tradução continua a apontar para o desejo de identificação da língua com uma nação e pátria e permanece como um dos traços identitários mais importantes do sujeito tradutor.

\section{Referências}

COMPAGNON, Antoine. O trabalho da citação. Tradução de Cleonice P.B. Mourão. Belo Horizonte: Editora UFMG, 1996.

FERREIRA, Aurélio Buarque de Holanda. Novo Dicionário Aurélio. Rio de Janeiro: Editora Nova Fronteira, 1975.

FOUCAULT, Michel. A arqueologia do saber. Tradução de Luiz F. B. Neves. Rio de Janeiro: Forense Universitária, 1997. 
A ordem do discurso: aula inaugural no Collège de France, pronunciada em 2 de dezembro de 1970. Tradução de Laura F. de A. Sampaio. São Paulo: Edições Loyola, 1996.

HOUAISS, Antônio. Dicionário Houaiss da língua portuguesa. Rio de Janeiro: Instituto Antônio Houaiss, Editora Objetiva, 2001.

ORLANDI, Eni P. Terra à vista: discurso do confronto: velho e novo mundo. São Paulo: Cortez, 1990.

INDURSKY, Freda. A fragmentação do sujeito em análise do discurso. In: INDURSKY, F. \& CAMPOS, Maria do Carmo (orgs). Discurso, memória,identidade. Sagra Luzzato: Porto Alegre, RS, 2000, p. 70-81.

PÊCHEUX, Michel. Semântica e Discurso: Uma crítica à Afirmação do Óbvio. Tradução de Eni Orlandi. Campinas: Ed. da UNICAMP, 1988.

Análise automática do discurso (AAD-69). Tradução de Eni Orlandi. In: GADET, F. e HAK, T (orgs.). Por uma análise automática do discurso: uma introdução à obra de Michel Pêcheux. Campinas: Ed. da UNICAMP, 1997a, pp. 61-162.

.A Leitura e os Leitores. 2ed. Campinas, SP: Pontes, 2003.

RÓNAI, Paulo. Escola de tradutores. Rio de Janeiro: Educom, 1976.

TORRINHA, Francisco. Dicionário Latino Português. 2ed. Porto: Junta Nacional de Educação, 1945.

Resumo: Este artigo apresenta um trabalho de análise do discurso do prefácio de autoria de Aurélio Buarque de Holanda Ferreira para o livro de Paulo Rónai, A Tradução Vivida, de 1975. Com base no referencial teórico da Análise do Discurso, concebida por Pêcheux, e a partir do desenvolvimento de um dispositivo analítico, aponta-se para a construção de um sujeitotradutor - vinculado à imagem da língua nacional e aos processos identitários que o constituem - que é resultado da movência. Esta leva o sujeitotradutor brasileiro de uma vinculação baseada na fidelidade religiosa a um alinhamento à língua nacional.

Abstract: This article presents a discourse analysis of the preface by Aurélio Buarque de Holanda Ferreira written for Paulo Rónai's book, A Tradução Vivida, published in 1975. Based on Discourse Analysis, the theoretical 
framework designed by Pêcheux, and through the development of an analytical device, this work hopes to show that the construction of the translator's subject position--linked both to the image of the national language and to the identity processes framing him--is the result of mouvance, leading the Brazilian translator from a religious fidelity to the national language toward an affiliation with it. 